\title{
Cardiovascular examination using hand-held cardiac ultrasound
}

\author{
Sam Jenkins ${ }^{1} \cdot$ Mohamed G. Shiha ${ }^{2} \cdot$ Eron Yones $^{2} \cdot$ James Wardley $^{3,4} \cdot$ Alisdair Ryding $^{3} \cdot$ Chris Sawh $^{3}$.

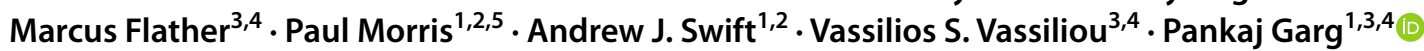

Received: 28 March 2021 / Revised: 10 June 2021 / Accepted: 20 July 2021 / Published online: 2 August 2021

(c) The Author(s) 2021

\begin{abstract}
Echocardiography is the first-line imaging modality for assessing cardiac function and morphology. The miniaturisation of ultrasound technology has led to the development of hand-held cardiac ultrasound (HCU) devices. The increasing sophistication of available HCU devices enables clinicians to more comprehensively examine patients at the bedside. HCU can augment clinical exam findings by offering a rapid screening assessment of cardiac dysfunction in both the Emergency Department and in cardiology clinics. Possible implications of implementing HCU into clinical practice are discussed in this review paper.
\end{abstract}

Keywords Hand-held cardiac ultrasound · Left ventricular ejection fraction · Wall motion abnormality · Left ventricular hypertrophy $\cdot$ Valvular heart disease $\cdot$ Jugular venous pressure

\section{Introduction}

Historically, the cardiovascular history and examination were the primary methods for screening cardiovascular disease. The advent of hand-held cardiac ultrasound (HCU) enables augmentation of the cardiovascular assessment at the bedside. These HCU devices enable subjective and quantitative assessment of cardiac morphology and function with reasonable diagnostic accuracy, even when used by inexperienced operators with basic training [1-5].

Echocardiography remains the first-line imaging test for the assessment of suspected cardiac pathology. Standard transthoracic echocardiogram (TTE) allows the determination of cardiac dysfunction by assessing LV cavity size, wall thickness, valvular appearance, and function, as well as for the presence of abnormal blood flow within the heart [6]. HCU technology is rapidly advancing. These devices may

Pankaj Garg

p.garg@uea.ac.uk

1 Department of Infection, Immunity and Cardiovascular Disease, University of Sheffield, Sheffield, UK

2 Sheffield Teaching Hospitals NHS Foundation Trust, Sheffield, UK

3 Norfolk and Norwich University Hospital, Norwich, UK

4 Norwich Medical School, University of East Anglia, Norwich, UK

5 Insigneo Institute for In Silico Medicine, Sheffield, UK ultimately bridge the gap between physical examination and TTE, allowing for more rapid clinical decision-making and a reduction in the rate of unnecessary TTE referrals.

In this comprehensive review, we aim to provide clinicians with a greater understanding of handheld ultrasound probe specifications and discuss the clinical utility of HCU for the augmentation of the physical cardiovascular examination. Devices available at the authors' institution were used to acquire images included in the current review.

\section{Available HCU hardware and specifications}

Multiple HCU devices are currently approved for clinical use and widely available including Clarius wireless scanner (Clarius, Canada), Lumify (Philips, USA), Vscan extend (General Electric, USA) and Butterfly iQ (Butterfly Network, USA) (Fig. 1). The Lumify device is not available at our institution and therefore images from this HCU device have not been included. All these devices can acquire images in B-mode, M-mode and colour Doppler. However, each scanner has different capabilities and specifications (Tables 1, 2). A comprehensive set of images, including pulse-wave Doppler of mitral inflow performed using Clarius PA HD in a healthy individual is shown in Fig. 2.

Currently available HCU devices are designed to be portable and lightweight whilst maintaining high technical specifications. The Butterfly iQ device is manufactured using a 


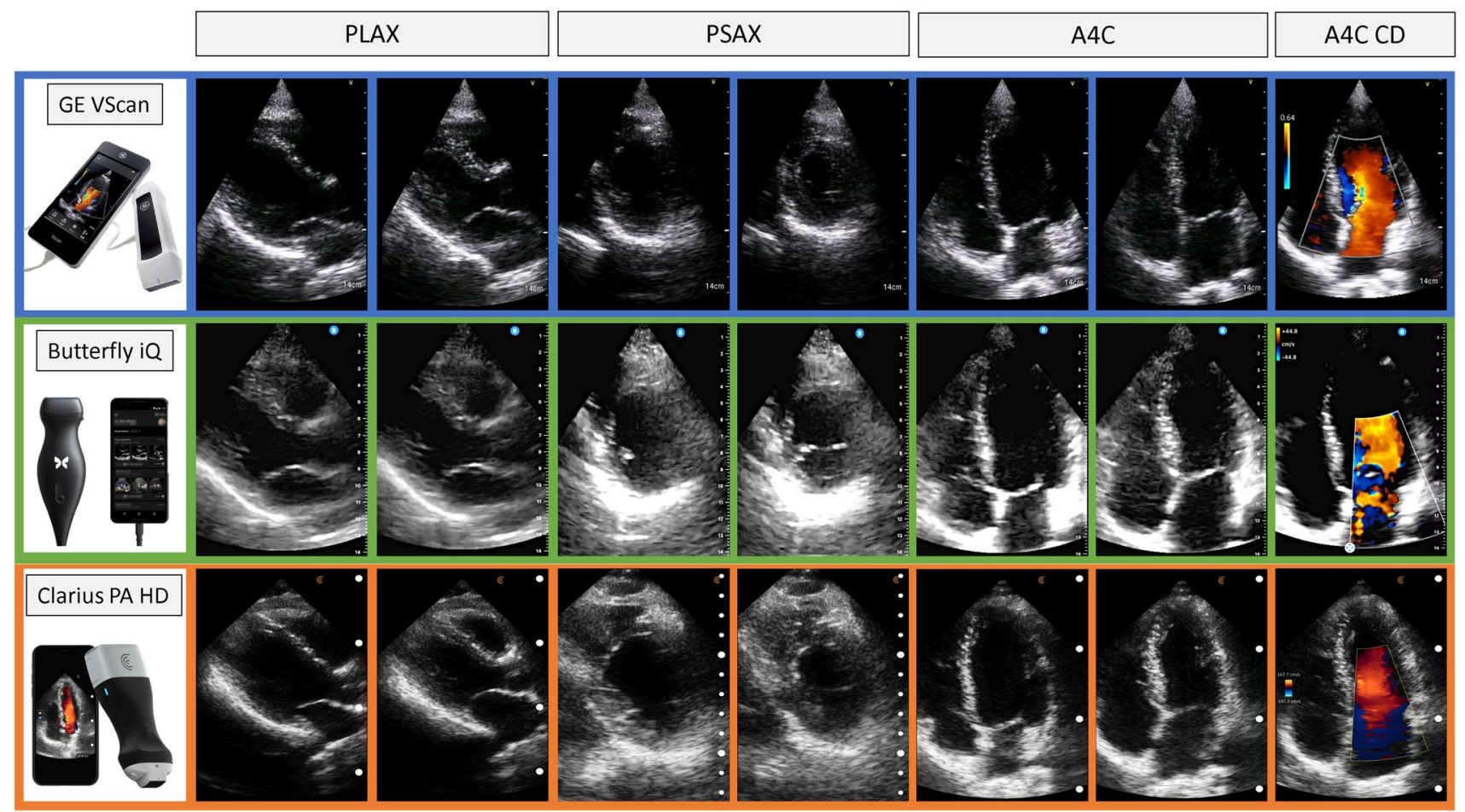

Fig. 1 Comparison of main handheld echocardiographic systems available. PLAX parasternal long axis, PSAX parasternal short axis, A4C apical 4-chamber, $C D$ colour Doppler

Table 1 HCU hardware and specifications

\begin{tabular}{|c|c|c|c|c|}
\hline \multirow[t]{2}{*}{ Specifications } & \multicolumn{4}{|l|}{ HCU device } \\
\hline & Butterfly iQ & Philips Lumify & GE Vscan extend & Clarius C3 HD \\
\hline Country & USA & USA & USA & Canada \\
\hline \multirow[t]{3}{*}{ Dimensions and weight } & $144 \times 53 \times 26 \mathrm{~mm}$ & C5-2 curved array (135 g) & $\begin{array}{l}\text { Display unit } \\
(168 \times 76 \times 22 \mathrm{~mm} \text {, weight } \\
321 \mathrm{~g})\end{array}$ & $164 \times 78 \times 38 \mathrm{~mm}$ \\
\hline & \multirow[t]{2}{*}{$313 \mathrm{~g}$} & L12-4 linear array $(108 \mathrm{~g})$ & $\begin{array}{l}\text { Dual probe } \\
\quad(129 \times 39 \times 28 \mathrm{~mm}, 120 \mathrm{~g})\end{array}$ & $392 \mathrm{~g}$ \\
\hline & & S4-1 phased array (96 g) & & \\
\hline \multirow[t]{2}{*}{ Price } & $\sim £ 1699+£ 360 /$ year & $\sim \$ 1200 / 6-\$ \sim 3360 / 24$ months & $\sim € 4250-\sim € 5100+$ Tax & $\sim £ 4050$ \\
\hline & 1-year warranty & 5 years warranty & $1-3$ years warranty & 3 years warranty \\
\hline \multirow[t]{2}{*}{ Probe } & Single probe ( 3 in 1 ) & $\begin{array}{l}3 \text { probes (curved C5-2, linear } \\
\text { L12-4, phased S4-1) }\end{array}$ & Dual probe (linear and sector) & Single probe \\
\hline & CMUT/CMOS based & & & Waterproof \\
\hline Cable & USB cable & USB cable & USB cable & Bluetooth and Wi-Fi \\
\hline Compatibility & IOS, Android & Android & GE Vscan display & IOS, Android \\
\hline \multirow[t]{2}{*}{ Data storage } & DICOM PACS & DICOM PACS & DICOM PACS & DICOM PACS \\
\hline & Cloud storage & Cloud storage & Cloud storage & Cloud storage \\
\hline \multirow[t]{3}{*}{ Battery } & $120 \min$ ( 2 continuous hours) & & $\begin{array}{l}\text { Continuous scan time of } \\
60 \mathrm{~min}\end{array}$ & Scan time: $\sim 60 \mathrm{~min}$ \\
\hline & $5 \mathrm{~h}$ (for full recharge) & & $\begin{array}{l}90 \mathrm{~min} \text { and recharged in } \\
75 \mathrm{~min}\end{array}$ & Charge time: $\sim 90 \mathrm{~min}$ \\
\hline & Wireless charging & & $\begin{array}{l}\text { Exchangeable batteries for } \\
\text { longer scan time }\end{array}$ & Standby: 7 days \\
\hline
\end{tabular}


Table 2 HCU clinical imaging and artificial intelligence specifications

\begin{tabular}{llllll}
\hline Specification & Functions & HCU device & & & \\
\cline { 3 - 6 } & & Butterfly iQ & Philips & GE Vscan & Clarius \\
Lumify & extend & C3 HD \\
\hline Imaging & & & $\sqrt{ }$ & $\sqrt{ }$ & $\sqrt{ }$ \\
& M & & $\sqrt{ }$ & $\sqrt{ }$ & $\sqrt{ }$ \\
& M-mode & $\sqrt{ }$ & $\sqrt{ }$ & $\sqrt{ }$ & $\sqrt{ }$ \\
& CDI & $\sqrt{ }$ & $\sqrt{ }$ & $\mathrm{x}$ & $\sqrt{ }$ \\
& PDI & $\sqrt{ }$ & $\mathrm{x}$ & $\mathrm{x}$ & $\sqrt{ }$ \\
& PWD & $\mathrm{x}$ & $\mathrm{x}$ & $\mathrm{x}$ & $\sqrt{ }$ \\
& Midline & $\sqrt{ }$ & $\mathrm{x}$ & $\sqrt{ }$ & $\sqrt{ }$ \\
& Measurements & $\sqrt{ }$ & $\mathrm{x}$ & $\sqrt{ }$ & 40 \\
& Scan depth (cm) & 30 & 30 & 24 & 8 \\
& Imaging presets (n) & 20 & 10 & 15 & $\mathrm{x}$ \\
Artificial Intelligence & Ejection fraction calculator & $\sqrt{ }$ & $\mathrm{x}$ & $\sqrt{ }$ & $\mathrm{x}$ \\
& Tele-guidance & $\sqrt{ }$ & $\sqrt{ }$ & $\mathrm{x}$ & $\sqrt{ }$ \\
& Auto optimise & $\mathrm{x}$ & $\sqrt{ }$ & $\sqrt{ }$ & $\sqrt{ }$ \\
& Bladder volume tool & $\sqrt{ }$ & $\mathrm{x}$ & $\sqrt{ }$ & $\mathrm{x}$ \\
& Apps from GE marketplace & $\mathrm{x}$ & $\mathrm{x}$ & $\sqrt{ }$ & $\mathrm{x}$ \\
\hline
\end{tabular}

$H C U$ hand-held cardiac ultrasound, 2D 2-dimensional, CDI colour Doppler imaging, PDI power Doppler imaging, $P W D$ pulse-wave Doppler

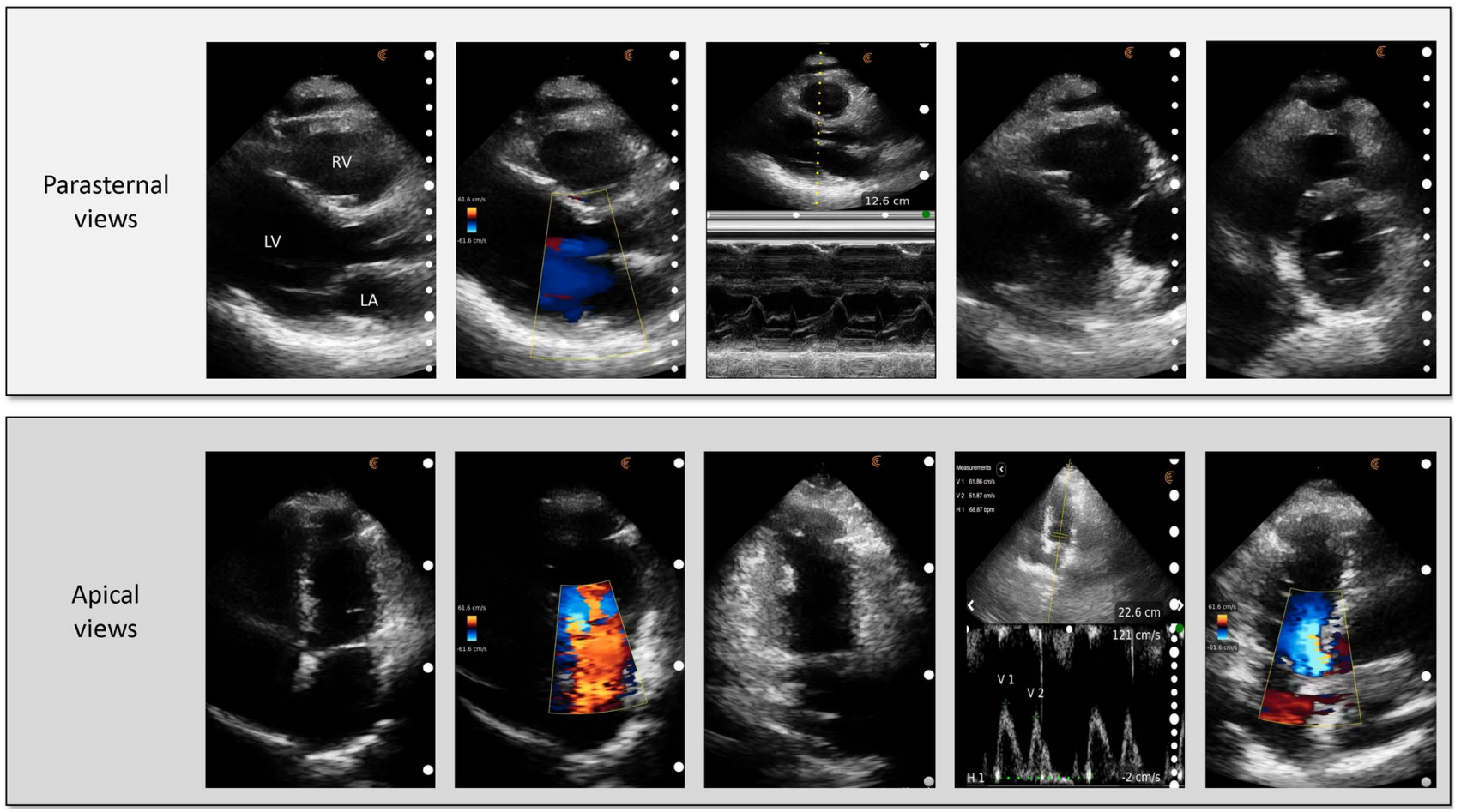

Fig. 2 Comprehensive cardiac examination by Clarius PA HD. B-mode, colour Doppler and M-mode are demonstrated in parasternal views. In apical views, similar views and pulse wave Doppler

complementary metal-oxide semiconductor (CMOS) material which allows mass production at a low cost, making this scanner one of the most affordable. HCU devices are compatible with Android, Android-like and iOS devices. for mitral inflow are demonstrated. V1=peak early filling velocity, $\mathrm{V} 2=$ peak late filling velocity

Images can therefore be interpreted remotely by experienced diagnosticians. This includes utilisation in rural areas and low-resource countries where conventional ultrasound is not easily accessible [7, 8]. Devices also offer Tele-Guidance 
allowing live directions from a remote ultrasound expert when obtaining and interpreting images. The Clarius ultrasound scanner has the unique advantage of being wireless making the device more accessible. During the Coronavirus disease 2019 (COVID-19) pandemic, HCU has increased in popularity due to its safety as the size of the devices makes them easier to disinfect compared to standard echocardiography machines [9].

The ultrasound technology incorporated into $\mathrm{HCU}$ devices is becoming increasingly more sophisticated. GE Vscan and Butterfly iQ have developed technology to automatically calculate left ventricular ejection fraction whilst Clarius ultrasound scanner is the only HCU device able to provide pulsed-wave Doppler technology. Butterfly iQ have introduced an educational view guidance tool that assesses the quality of the images acquired in real-time to enhance scanning technique.

\section{Limitations of HCU devices}

Battery life limits the use of $\mathrm{HCU}$ and therefore is indicated for quick scans. Vscan has an exchangeable battery which allows for longer scanning times compared to other devices. Continuous imaging can lead to the device freezing to allow for cooling which also limits the length of time they can be used.

Spectral Doppler technology causes HCU devices to heat up more rapidly and is one reason for only a few models incorporating these imaging modalities. Clarius is one of the only scanners on the market capable of PWD, permitted by the installation of a liquid heating device which prevents overheating [10]. This feature allows for quantitative assessment of cardiac pathologies including left ventricular filling pressures (i.e. diastolic function) calculated by measuring the E/A ratio and right ventricular dysfunction. This has the potential to offer significant value in the bedside assessment, diagnosis and monitoring of patients either with suspected or decompensating heart failure. Continuous-wave Doppler is also not a readily available feature of HCU devices. This modality would allow for quantitative assessment of high velocities across valves which could confirm aortic stenosis or regurgitation, mitral stenosis or tricuspid regurgitation. Currently, clinical suspicion of valvular heart disease or auscultation of murmurs can only be qualitatively assessed by the majority of HCU devices using standard B-mode and colour-flow Doppler.

The availability of HCU varies between departments, institutions and countries. For example, Butterfly is not commercially available in Japan compared to the UK where it occupies a large share of the market. Although this review aims to describe the range of specifications of individual
HCU devices, there is little research into the impact of these varying specifications on their diagnostic ability.

\section{Clinical applications}

Point-of-care ultrasound (POCUS) has rapidly transformed over the past two decades beyond the large machines that were initially introduced into emergency medicine and critical care. The advancement of POCUS technology has led to the introduction of more portable, handheld devices which are now also used in obstetrics to confirm intrauterine pregnancies, rheumatology to image for joint and soft tissue injuries and gastroenterology in the diagnosis of appendicitis and gallbladder pathology [11]. One of the most common indications for POCUS is suspected cardiac pathology. HCU is a focused, bedside, point of care examination which, in combination with clinical examination, ECG, blood results, and standard X-Ray can augment and enhance clinical diagnosis of a number of acute cardiac conditions. Positive and negative findings should be sought actively and documented clearly. Where there is doubt around HCU findings, these images should be reviewed by a senior sonographer or cardiologist. Intervention and treatment should not be commenced in cases where there is operator doubt about HCU imaging findings. With experience and increased caseload, HCU operator diagnostic and imaging skills will improve and over time, help provide good clinical data to allow early intervention and management of many conditions, aid discharge without need to wait for formal departmental TTE as well as help rapidly rule out various cardiac conditions.

\section{LV size and systolic function}

Physical signs of impaired LV systolic function often only manifest when there is advanced disease. HCU can identify evidence of declining cardiac function in asymptomatic patients allowing for earlier commencement of treatment, thus limiting the development of cardiac failure. HCU permits the assessment of left ventricular morphology and function by estimating LVEF and detecting regional wall motion abnormalities (WMA) [4, 12-14]. These methods can yield greater clinical value compared to physical examination [15]. Auscultation of S3 is rarely found in patients with LV systolic dysfunction whilst pulmonary oedema is an insensitive sign and may only present when the disease is severe [16].

Rapid HCU assessment and identification of regional WMAs may help confirm a diagnosis of acute myocardial infarction (MI) in patients with chest pain who have an equivocal or non-localising ECG and/or indeterminate laboratory markers [17]. HCU may also offer initial estimates of baseline LV function following MI [18]. Assessment of 
LV function and presence of LV thrombus after myocardial infarction, especially anterior ST-segment elevation myocardial infarction, is important for both treatment and prognostic considerations. Detection of poor LV systolic function favours a diagnosis of heart failure (HF) instead of pneumonia or chronic obstructive disease exacerbation in patients presenting with non-specific symptoms. This subgroup of patients could subsequently benefit from earlier referral for further imaging and potentially avoid unnecessary tests. The impact of valvular disease on cardiac function can be quantified by estimating LVEF. Periodic repeat assessment using HCU may be able to give an indication of advancing disease severity. These assessments can be conducted by specialist nurses in outpatient clinics or in the community providing potential detection of worsening function and referral to TTE before the patient becomes symptomatic [19-21]. Concurrent assessment of left ventricular hypertrophy (LVH) and LV dilatation when evaluating LV function can help grade the severity of cardiac disease or confirm clinical suspicions when individual findings are ambiguous.

\section{LV diastolic assessment}

Routine TTE examination for LV filling pressure involves tissue Doppler imaging (TDI) to measure LV myocardial velocities ( $\mathrm{e}^{\prime}$ and $\left.\mathrm{a}^{\prime}\right)$, pulse-wave Doppler for mitral inflow velocities (E and A) and continuous-wave Doppler for measuring peak TR velocity. Current probes do not offer all these ultrasound technologies, hence LV diastolic assessment is limited to mitral inflow assessment by some probes which offer pulse-wave Doppler assessment. Nevertheless, left atrial size can be estimated by HCU and this is also routinely advocated for estimating LV filling pressures.

\section{Left atrial assessment}

Left atrial assessment can be made easily by apical 4-chamber and 2-chamber views. These views are relatively simple to acquire by HCU. These views allow us to quantify both the left atrial area and volume. HCU can more sensitively detect left atrial enlargement compared with auscultation of S4 on clinical examination [14, 22-25]. Grading severity of mitral valve disease can be aided by measuring the diameter of the left atrium. Repeat imaging can assess the response to intervention post-surgery.

\section{Valvular heart disease assessment}

Quantitative assessment of valvular heart disease (VHD) using HCU is limited because pulse-wave and continuouswave Doppler modalities are not available with the majority of probes. Imaging for valvular insufficiencies or morphological abnormalities of stenotic valves, therefore, relies on qualitative colour-Doppler and B-mode assessment. Initial assessment following a clinical suspicion of VHD can determine whether the patient requires further investigation. Repeat imaging can also provide complementary information to clinical examination regarding disease progression, which can support a decision to refer for more complex imaging.

\section{Right ventricular size and function}

Early detection of right ventricular (RV) enlargement and hypokinesis can improve the prognosis of acutely unwell patients such as those admitted with an undiagnosed pulmonary embolism (PE). The majority of fatal PEs occur within the first few hours of developing symptoms, with $30-50 \%$ remaining undiagnosed until autopsy [26, 27]. Rapid and accurate assessment of the RV using HCU can lead to a more efficient diagnosis, administration of treatment and improved prognosis, as findings can necessitate the urgent results of tests such as D-dimer in high-risk patients. RV end-diastolic diameter has been shown to be the most sensitive predictor of PE which can be measured using HCU. Subjective measures including hypokinesis and McConnell's sign of free wall dyskinesia show poor sensitivity for the diagnosis of PE. Tricuspid annular plane systolic excursion shows reasonable sensitivity and could be measured using the M-mode modality of HCU devices. TTE does allow for quantitative assessment of RV dysfunction by measuring the tricuspid regurgitant jet velocity. This is almost exclusive to TTE as it requires continuous-wave Doppler [28, 29]. Estimates of systolic pulmonary arterial pressure (sPAP) to detect pulmonary arterial hypertension (PAH) have shown only moderate diagnostic accuracy when performed using HCU devices capable of CWD [18, 30, 31]. Low thresholds for bedside HCU assessment of patients with non-specific signs and symptoms may allow for earlier TTE referral and diagnosis of PAH, which is commonly only diagnosed at an advanced stage [32].

\section{Pericardial disease}

The presence of an anechoic space within the pericardium, right atrial inversion or right ventricular diastolic collapse indicates pericardial effusion. These measurements using HCU can specifically predict pericardial effusions $[14,18$, 33]. One limitation includes epicardial fat being misinterpreted as an effusion, especially when the operator is less experienced. Assessing respiratory variation of the mitral or tricuspid inflow velocities and the aortic flow velocity is limited to pulse-wave Doppler probes. Few HCU devices can offer this function whilst TTE routinely examines these entities allowing for quantitative assessment of pericardial disease. Assessment for pericardial fluid or tamponade in 
patients with myocardial infarction, myocarditis and pericarditis are important to guide investigation, therapy and discharge planning.

\section{Haemodynamic assessment}

Ultrasound examination of jugular venous pressure (U-JVP) can be used to estimate a patient's fluid status by identifying the collapse point of the internal jugular vein (IJV). The collapse point is viewed in the longitudinal axis with the patient positioned in a semi-upright position (Fig. 3). The location of the jugular venous pulsations is highly subjective and accuracy of the physical examination varies significantly between clinicians [34]. HCU removes this subjectivity and can be easily viewed even by inexperienced operators. U-JVP allows visualisation of the venous collapse which would otherwise be undetectable by a physical examination in obese patients. However, U-JVP has limitations as estimates of fluid status become less specific in hypovolaemic

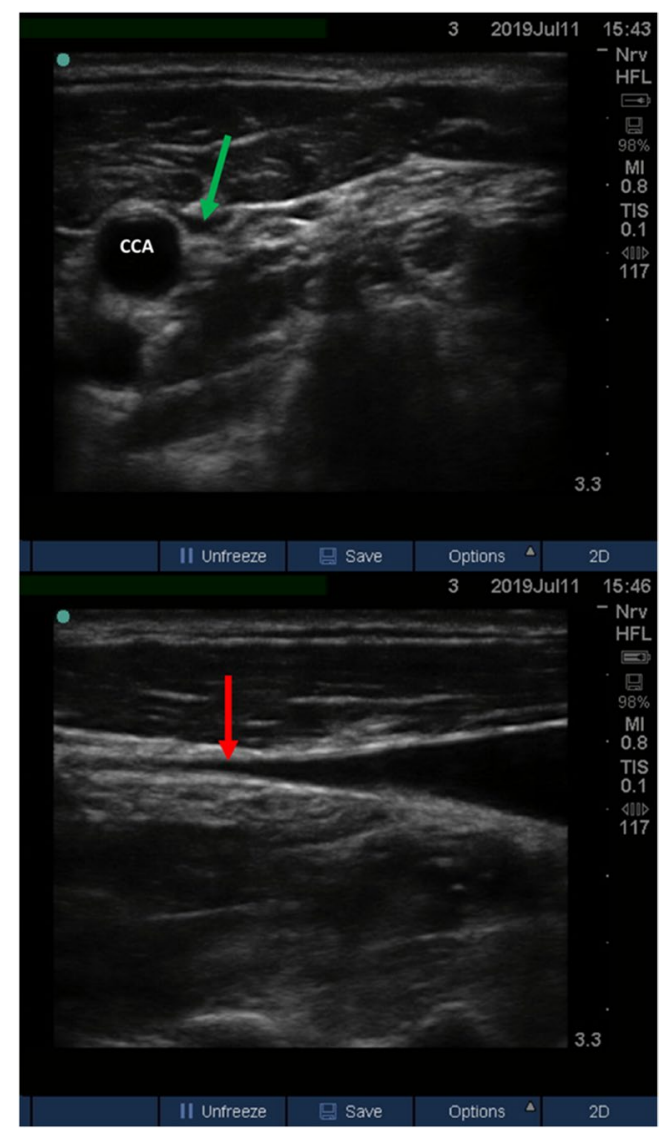

Fig. 3 Ultrasound-measured jugular venous pressure imaged in a semi-recumbent position. Top: transverse view of a collapsed IJV. The green arrow points towards the collapsed IJV. Bottom: longitudinal axis of the IJV. The IJV tapers until reaching the point of collapse. The red arrow indicates the point at which the vein is collapsed. $C C A$ common carotid artery, $I J V$ internal jugular vein patients [35]. In an emergency setting, the patient may be required to lie supine. In this scenario, U-JVP would not be viable and imaging of inferior vena cava (IVC) diameter and collapsibility would be required to estimate fluid status. IVC assessment in the subcostal view is the standard non-invasive bedside imaging method for estimating haemodynamic status. A greater amount of training to achieve basic competence in IVC image acquisition may be required compared to simple imaging of the jugular venous collapse point. However, IVC diameter and collapsibility can give a quantitative measure of fluid status and once sufficiently trained, sensitivity of the technique can reach up to $93 \%$ by experienced cardiologists [13]. In contrast, the accuracy of the height of the collapsing jugular vein above the right atrium as a measure of fluid status has been variably reported and may best be used as a simple, quick-look, qualitative assessment [35, 36].

\section{Training}

Minimal training is required to gain basic competency in image acquisition using HCU [33]. Although 20-30 scans have been deemed acceptable to develop basic skills in ultrasound, accurate and reliable interpretation of images requires repeated exposure over a prolonged period of time [37]. The ability of images to be stored enables less experienced operators to request interpretation by more senior colleagues. This can limit the number of false-positive results which commonly occur among inexperienced users, especially when only having undertaken limited training [38]. Experience has been repeatedly shown to impact the diagnostic accuracy of HCU examinations. Level II/III echocardiographers are able to more accurately diagnose cardiac pathology compared to inexperienced operators with limited echocardiography training [33, 39-41]. This suggests that standard echocardiography training is fundamental to competently acquire and interpret images, as opposed to training solely with an HCU device. Positive results need to be interpreted with caution, especially when performed by inexperienced $\mathrm{HCU}$ users. Clinical decision-making should not be solely guided by the interpretation of $\mathrm{HCU}$ images, even by experienced echocardiographers. Instead, HCU should act as an initial diagnostic test to aid decision-making on whether further investigation including TTE and treatment is required.

The lack of a designated HCU training pathway, certification and hospital service poses a barrier to the implementation of bedside imaging in clinical practice. Levels of competence cannot be standardised and the absence of HCU services means clinicians cannot gain the experience necessary to acquire and interpret images with consistently high accuracy. Ultrasound education has been implemented in American medical school curriculums for more than a decade which is currently not available in the UK [42]. Such 
training aids students' understanding of clinical anatomy and development of basic ultrasound skills as well as their diagnostic ability [5, 43]. However, this relies on sufficiently trained tutors being available which may incur geographical bias between schools. HCU services must also be available upon graduation to maintain their level of skill.

\section{Cost-effectiveness}

HCU has been associated with reduced costs when compared with standard echocardiography $[15,44,45]$. Verification of clinical exam findings using HCU means that the rate of unnecessary TTE referrals could be reduced [15]. It is important to stress that HCU does not replace TTE and any abnormal or uncertain findings should be confirmed with further imaging. An increase in the use of HCU imaging could lead to a paradoxical increase in TTE referrals due to a rise in the number of incidental findings. The use of HCU by community nurses may enable further savings by monitoring patients with HF. This could allow for earlier detection of advancing disease, reducing the risk of further complications and need for more complex interventions. A substantial potential cost relates to the implementation of HCU services and provision of the appropriate training. Restructuring of the standard echocardiography pathway and development of standardised levels of competency are required to integrate $\mathrm{HCU}$ into routine practice, which has complex logistical and financial implications.

\section{Conclusion}

The increasing sophistication of available HCU devices enables clinicians to more comprehensively examine patients at the bedside. HCU can augment clinical exam findings by offering a rapid screening assessment of cardiac dysfunction in both the Emergency Department and in cardiology clinics. Possible implications of implementing HCU into clinical practice are earlier detection of cardiac pathology and a reduction in unnecessary TTE referrals.

\begin{abstract}
Author contributions SJ and PG contributed to the study conception and design. Material preparation, data collection, and analysis were performed by SJ, MS, EJ, and PG. The first draft of the manuscript was written by SJ and all authors commented on previous versions of the manuscript. All authors read and approved the final manuscript.
\end{abstract}

Funding This work was funded in part by the Wellcome Trust [215799/Z/19/Z, 214567/Z/18/Z and 205188/Z/16/Z. For the purpose of Open Access, the author has applied a CC BY public copyright licence to any Author Accepted Manuscript version arising from this submission.

\section{Declarations}

Conflict of interest PG is an advisor for Pie Medical Imaging and Medis Medical Imaging. James Wardley lists commercial relationships with AstraZeneca, Bayer and Novartis. Sam Jenkins, Mohamed Shiha, Eron Jones, Alisdair Ryding, Chris Sawh, Marcus Flather, Andrew Swift and Vassilios Vassiliou declare no conflicts of interest.

Research involving human participants and/or animals This review article does not contain any studies with human or animal subjects performed by any of the authors.

Open Access This article is licensed under a Creative Commons Attribution 4.0 International License, which permits use, sharing, adaptation, distribution and reproduction in any medium or format, as long as you give appropriate credit to the original author(s) and the source, provide a link to the Creative Commons licence, and indicate if changes were made. The images or other third party material in this article are included in the article's Creative Commons licence, unless indicated otherwise in a credit line to the material. If material is not included in the article's Creative Commons licence and your intended use is not permitted by statutory regulation or exceeds the permitted use, you will need to obtain permission directly from the copyright holder. To view a copy of this licence, visit http://creativecommons.org/licenses/by/4.0/.

\section{References}

1. Aldaas OM, Igata S, Raisinghani A, Kraushaar M, DeMaria AN. Accuracy of left ventricular ejection fraction determined by automated analysis of handheld echocardiograms: a comparison of experienced and novice examiners. Echocardiography. 2019;36:2145-51.

2. Bruce CJ, Montgomery SC, Bailey KR, Tajik J, Seward JB. Utility of hand-carried ultrasound devices used by cardiologists with and without significant echocardiographic experience in the cardiology inpatient and outpatient settings. Am J Cardiol. 2002;90:1273-5.

3. Gulič TG, Makuc J, Prosen G, Dinevski D. Pocket-size imaging device as a screening tool for aortic stenosis. Wien Klin Wochenschr. 2016;128:348-53.

4. Liebo MJ, Israel RL, Lillie EO, Smith MR, Rubenson DS, Topol EJ. Pocket mobile echocardiography: the next-generation stethoscope? A comparison of rapidly acquired PME images to standard TTE. Ann Intern Med. 2011;155:33-8.

5. Stokke TM, Ruddox V, Sarvari SI, Otterstad JE, Aune E, Edvardsen T. Brief group training of medical students in focused cardiac ultrasound may improve diagnostic accuracy of physical examination. J Am Soc Echocardiogr. 2014;27:1238-46.

6. Wharton G, Steeds R, Allen J, Phillips H, Jones R, Kanagala $\mathrm{P}$, et al. A minimum dataset for a standard adult transthoracic echocardiogram: a guideline protocol from the British Society of Echocardiography. Echo Res Pract. 2015;2:G9-24.

7. Epstein D, Petersiel N, Klein E, Marcusohn E, Aviran E, Harel $\mathrm{R}$, et al. Pocket-size point-of-care ultrasound in rural Uganda - a unique opportunity "to see", where no imaging facilities are available. Travel Med Infect Dis. 2018;23:87-93.

8. Henwood PC, Mackenzie DC, Liteplo AS, Rempell JS, Murray AF, Leo MM, et al. Point-of-care ultrasound use, accuracy, and impact on clinical decision making in Rwanda Hospitals. J Ultrasound Med. 2017;36:1189-94. 
9. Buonsenso D, Pata D, Chiaretti A. COVID-19 outbreak: less stethoscope, more ultrasound. Lancet Respir Med. 2020;8:e27.

10. C3 overview - handheld curvilinear ultrasound scanner - Clarius [internet]. Clarius Mobile Health. https://clarius.com/gb/scanners/ c3/. Accessed 24 May 2021.

11. Arnold MJ, Jonas CE, Carter RE. Point-of-care ultrasonography. Am Fam Physician. 2020;101:275-85.

12. DeCara JM, Lang RM, Koch R, Bala R, Penzotti J, Spencer KT. The use of small personal ultrasound devices by internists without formal training in echocardiography. Eur J Echocardiogr. 2003;4:141-7.

13. Khan HA, Wineinger NE, Uddin PQ, Mehta HS, Rubenson DS, Topol EJ. Can hospital rounds with pocket echocardiography by cardiologists reduce standard transthoracic echocardiography? Am J Med. 2014;127:669.e1-669.e7.

14. Xie T, Chamoun AJ, McCulloch M, Tsiouris N, Birnbaum Y, Ahmad M. Rapid screening of cardiac patients with a miniaturized hand-held ultrasound imager-comparisons with physical examination and conventional two-dimensional echocardiography. Clin Cardiol. 2006;27:241-5.

15. Mehta M, Jacobson T, Peters D, Le E, Chadderdon S, Allen AJ, et al. Handheld ultrasound versus physical examination in patients referred for transthoracic echocardiography for a suspected cardiac condition. JACC Cardiovasc Imaging. 2014;7:983-90.

16. Martindale JL, Wakai A, Collins SP, Levy PD, Diercks D, Hiestand $\mathrm{BC}$, et al. Diagnosing acute heart failure in the emergency department: a systematic review and meta-analysis. Acad Emerg Med. 2016;23:223-42.

17. Panoulas VF, Daigeler A-L, Malaweera ASN, Lota AS, Baskaran D, Rahman S, et al. Pocket-size hand-held cardiac ultrasound as an adjunct to clinical examination in the hands of medical students and junior doctors. Eur Heart J Cardiovasc Imaging. 2013;14:323-30.

18. Vignon P, Frank MBJ, Lesage J, Mücke F, François B, Normand $\mathrm{S}$, et al. Hand-held echocardiography with Doppler capability for the assessment of critically-ill patients: is it reliable? Intensive Care Med. 2004;30:718-23.

19. Dalen H, Gundersen GH, Skjetne K, Haug HH, Kleinau JO, Norekval TM, et al. Feasibility and reliability of pocket-size ultrasound examinations of the pleural cavities and vena cava inferior performed by nurses in an outpatient heart failure clinic. Eur J Cardiovasc Nurs. 2015; 14:286-93.

20. Graven T, Wahba A, Hammer AM, Sagen O, Olsen Ø, Skjetne $\mathrm{K}$, et al. Focused ultrasound of the pleural cavities and the pericardium by nurses after cardiac surgery. Scand Cardiovasc J. 2015;49:56-63.

21. Kirkpatrick JN, Belka V, Furlong K, Balasia B, Jacobs LD, Corcoran M, et al. Effectiveness of echocardiographic imaging by nurses to identify left ventricular systolic dysfunction in high-risk patients. Am J Cardiol. 2005;95:1271-2.

22. Borkowsky S, Charles-Damte M, Fung S, Patel M, Mba B, Margeta B, et al. Diagnostic accuracy of hospitalist-performed hand-carried ultrasound echocardiography after a brief training program. J Hosp Med. 2009;4. https://www.journalofhospitalmed icine.com/jhospmed/article/128374/accuracy-hospitalist-perfo rmed-hcue. Accessed 7 Apr 2020.

23. Mjølstad OC, Andersen GN, Dalen H, Graven T, Skjetne K, Kleinau JO, et al. Feasibility and reliability of point-of-care pocketsize echocardiography performed by medical residents. Eur Heart J Cardiovasc Imaging. 2013;14:1195-202.

24. Morrison LK, Harrison A, Krishnaswamy P, Kazanegra R, Clopton P, Maisel A. Utility of a rapid B-natriuretic peptide assay in differentiating congestive heart failure from lung disease in patients presenting with dyspnea. J Am Coll Cardiol. 2002;39:202-9.
25. Kono Y, Fukuda S, Shimada K, Oe H, Maeda K, Kawasaki T, et al. Pocket-sized echo for evaluation of mitral and tricuspid regurgitation. JACC Cardiovasc Imaging. 2011;4:921.

26. Dresden S, Mitchell P, Rahimi L, Leo M, Rubin-Smith J, Bibi S, et al. Right ventricular dilatation on bedside echocardiography performed by emergency physicians aids in the diagnosis of pulmonary embolism. Ann Emerg Med. 2014;63:16-24.

27. Heit JA, Spencer FA, White RH. The epidemiology of venous thromboembolism. J Thromb Thrombolysis. 2016;41:3-14.

28. Rudski LG, Lai WW, Afilalo J, Hua L, Handschumacher MD, Chandrasekaran K, et al. Guidelines for the echocardiographic assessment of the right heart in adults: a report from the American Society of Echocardiography endorsed by the European Association of Echocardiography, a registered branch of the European Society of Cardiology, and the Canadian Society of Echocardiography. J Am Soc Echocardiogr. 2010;23:685-713.

29. Zoghbi WA, Enriquez-Sarano M, Foster E, Grayburn PA, Kraft CD, Levine RA, et al. Recommendations for evaluation of the severity of native valvular regurgitation with two-dimensional and Doppler echocardiography. J Am Soc Echocardiogr. 2003; 16:777-802.

30. Goodkin GM, Spevack DM, Tunick PA, Kronzon I. How useful is hand-carried bedside echocardiography in critically ill patients? J Am Coll Cardiol. 2001;37:2019-22.

31. Vignon P, Chastagner C, François B, Martaillé J-F, Normand S, Bonnivard M, et al. Diagnostic ability of hand-held echocardiography in ventilated critically ill patients. Crit Care. 2003;7:R84-91.

32. Brown LM, Chen H, Halpern S, Taichman D, McGoon MD, Farber HW, et al. Delay in recognition of pulmonary arterial hypertension. Chest. 2011;140:19-26.

33. Andersen GN, Haugen BO, Graven T, Salvesen $\varnothing$, Mjølstad OC, Dalen H. Feasibility and reliability of point-of-care pocket-sized echocardiography. Eur J Echocardiogr. 2011;12:665-70.

34. Rizkallah J, Jack M, Saeed M, Shafer LA, Vo M, Tam J. Noninvasive bedside assessment of central venous pressure: scanning into the future. PLoS One. 2014;9. https://www.ncbi.nlm.nih.gov/ pmc/articles/PMC4184858/. Accessed 24 Mar 2020.

35. Avcil M, Kapci M, Dagli B, Omurlu IK, Ozluer E, Karaman K, et al. Comparision of ultrasound-based methods of jugular vein and inferior vena cava for estimating central venous pressure. Int J Clin Exp Med. 2015;8:10586-94.

36. Deol GR, Collett N, Ashby A, Schmidt GA. Ultrasound accurately reflects the jugular venous examination but underestimates central venous pressure. Chest. 2011;139:95-100.

37. Hellmann DB, Whiting-O'Keefe Q, Shapiro EP, Martin LD, Martire C, Ziegelstein RC. The rate at which residents learn to use hand-held echocardiography at the bedside. Am J Med. 2005;118:1010-8.

38. Wilkinson JS, Barake W, Smith C, Thakrar A, Johri AM. Limitations of condensed teaching strategies to develop hand-held cardiac ultrasonography skills in internal medicine residents. Can J Cardiol. 2016;32:1034-7.

39. Galasko GIW, Lahiri A, Senior R. Portable echocardiography: an innovative tool in screening for cardiac abnormalities in the community. Eur J Echocardiogr. 2003;4:119-27.

40. Nilsson G, Söderström L, Alverlind K, Samuelsson E, Mooe T. Hand-held cardiac ultrasound examinations performed in primary care patients by nonexperts to identify reduced ejection fraction. BMC Med Educ. 2019;19:282.

41. Ruddox V, Stokke TM, Edvardsen T, Hjelmesæth J, Aune E, Bækkevar M, et al. The diagnostic accuracy of pocket-size cardiac ultrasound performed by unselected residents with minimal training. Int J Cardiovasc Imaging. 2013;29:1749-57.

42. Hoppmann RA, Rao VV, Bell F, Poston MB, Howe DB, Riffle $S$, et al. The evolution of an integrated ultrasound curriculum 
(iUSC) for medical students: 9-year experience. Crit Ultrasound J. 2015;7:18.

43. Hammoudi N, Arangalage D, Boubrit L, Renaud MC, Isnard R, Collet J-P, et al. Ultrasound-based teaching of cardiac anatomy and physiology to undergraduate medical students. Arch Cardiovasc Dis. 2013;106:487-91.

44. Pathan F, Fonseca R, Marwick TH. Usefulness of hand-held ultrasonography as a gatekeeper to standard echocardiography for "rarely appropriate" echocardiography requests. Am J Cardiol. 2016;118:1588-92.
45. Greaves K, Jeetley P, Hickman M, Dwivedi G, Sabharwal N, Lim $\mathrm{T}$, et al. The use of hand-carried ultrasound in the hospital settinga cost-effective analysis. J Am Soc Echocardiogr. 2005;18:620-5.

Publisher's Note Springer Nature remains neutral with regard to jurisdictional claims in published maps and institutional affiliations. 